ISSN: $1130-3743$

\title{
PENSAR Y HACER HOY EDUCACIÓN MORAL
}

\author{
To think about and to do moral education today
}

Penser et faire aujourd'bui l'éducation morale

Juan ESCÁMEZ SÁNCHEZ

Universidad de Valencia

\section{ANTECEDENTES DE LA ACTUAL INVESTIGACIÓN EN EDUCACIÓN MORAL}

La educación moral consiste en el proceso de enseñanza y aprendizaje por el que el individuo va configurándose como una persona moral. Lo que sea una persona moral se ha entendido de muy diversas maneras, por lo que también se dan distintas concepciones de la educación moral. La historia de las teorías éticas tiene un correlato, a veces implícito y otras explícito, en las concepciones de la educación moral. Tres han sido las teorías contemporáneas de la educación moral que han prevalecido sobre las demás hasta mediados los años noventa del siglo pasado: la formación del carácter, el desarrollo del juicio moral y la filosofía para niños; algunos, entre los que no me encuentro, también consideran a la clarificación de valores como otra teoría de la educación moral.

La concepción de la educación moral como formación del carácter hunde sus raíces en la tradición griega. Para los griegos, ético significaba un modo de ser o carácter que se adquiría a través de las propias acciones y concebían como vida buena aquella que estaba entregada al bien de la ciudad. La persona de carácter bueno o ética era aquella que tenía las cualidades necesarias para desempeñar adecuadamente un papel en el funcionamiento de su ciudad o comunidad política; el ideal de persona ética o de carácter bueno coincidía con el ideal de ciudadano. Bien es cierto que en Sócrates y, sobre todo, en Platón se insiste que sólo el que conoce el bien podrá prestar un buen servicio a la ciudad pero, inmersos en la tradición homérica, atribuyen a todo el proceso de adquisición del conocimiento del bien la finalidad de servir a la comunidad política. 
¿Cómo se educa el carácter? Aristóteles, más homérico que su maestro Platón, considera que para formar el carácter lo más adecuado es aplicarse a la realización de acciones. El aprendizaje por cualquier persona de las cualidades como ciudadano, o cualidades morales (que llama "virtudes"), tiene como punto de partida la imitación de quienes son considerados por la comunidad como los mejores ciudadanos; quien así lo hace, puede conseguir el conocimiento para hacer juicios racionales sobre lo que es bueno; quien no cultiva primero las cualidades ciudadanas será incapaz de juzgar rectamente qué es lo bueno. Las acciones que el sujeto realiza, de acuerdo al ideal de ciudadano excelente, le conducirán al autodominio, la disciplina y la transformación, cuando sea necesaria, de los deseos y sentimientos. En el ejercicio de esas acciones en beneficio de la ciudad, los sujetos van adquiriendo la comprensión de la vida buena y el disfrute de la felicidad que proporciona ese modo de vivir verdaderamente humano.

La tradición moral griega es el horizonte filosófico desde donde surgen las actuales concepciones éticas y políticas, conocidas como "comunitaristas". Tales concepciones consideran que la persona se va configurando autobiográficamente en las relaciones de intercambio que establece con la comunidad a la que pertenece. La identidad de cada persona se forma por referencia a su comunidad, de tal manera que sin esa referencia es ininteligible. La lengua, las costumbres, los valores y las prácticas sociales compartidas son el sustrato cultural y social desde el que se articulan los derechos y los deberes de cada uno de los miembros de la comunidad; las metas que han de ser realizadas por una persona moral, las metas de la vida buena, no las establece cada uno de los individuos, de modo independiente y aislado de los otros miembros de su comunidad, sino que son metas comunes que responden a valores compartidos sobre lo que es digno de ser preferido por todos. El bien público o de la comunidad es la clave de la vida política, de la moral y del derecho.

El bien de la comunidad política se garantiza por la educación de todos los ciudadanos en unos valores morales básicos, que permiten el funcionamiento vigoroso de las sociedades democráticas: el respeto a las personas y al medio, la responsabilidad, la solidaridad, la tolerancia y la veracidad son los principales valores. Por ello, quienes conciben actualmente la educación moral como educación del carácter proponen socializar a los jóvenes a través de procedimientos pedagógicos que faciliten la interiorización de tales valores para que los diversos miembros de la comunidad política actúen de acuerdo a ellos en sus prácticas sociales. Entre tales procedimientos, se considera fundamental la implicación de las familias y los líderes de la comunidad en los proyectos educativos de los centros, así como el compromiso de los centros y los estudiantes con el servicio a sus comunidades próximas. Como estrategias y técnicas de aula se postulan: la conducta modélica del profesor que trata a los alumnos con amor y respeto; un clima del aula que facilite el cuidado de unos por otros; la práctica de la disciplina, usando las normas como oportunidades de ejercitar el autocontrol; un clima democrático de aula en el que los estudiantes intervienen en la formulación de las normas de funcionamiento y 
en el proceso de toma de decisiones; la explicación y aprendizaje de los valores mencionados anteriormente; el uso de técnicas cooperativas para generar habilidades de ayuda y de trabajo conjunto; el deseo de superación académica como una responsabilidad moral; la promoción de la reflexión moral a través de lecturas, escritos o debates y la enseñanza de procedimientos de solución de conflictos interpersonales.

La segunda modalidad de concebir la educación moral es el desarrollo del juicio moral. Los seguidores de esta teoría consideran que una adecuada educación moral es aquella que proporciona el progresivo ascenso de un estadio del juicio moral a otro estadio superior, hasta que el sujeto alcance un estadio de juicio sobre lo que debe ser hecho desde principios morales universales, como el principio moral de la dignidad humana. El representante más importante de esta teoría es L. Kohlberg.

Los orígenes filosóficos de esta concepción de la educación moral están en Kant, para quien persona moral es aquella que actúa por respeto a la ley que hay en su conciencia. Kant sostiene que la persona tiene dignidad y no precio, y ello es debido a su capacidad de sustraerse al orden natural, puesto que es capaz de dictar sus leyes sobre lo que debe hacerse, es autolegisladora o autónoma. El ámbito moral es el de la realización de la autonomía humana. La persona es lo absolutamente valioso y, por lo tanto, lo que hay que conservar y promocionar. Además de Kant, las otras fuentes de la teoría del desarrollo del juicio moral son Dewey y Piaget. De Dewey adopta la idea de la educación como desarrollo y, así, concibe la educación moral como el desarrollo progresivo desde el nivel preconvencional al postconvencional. Piaget tiene una gran influencia, tanto por la orientación empírica de sus investigaciones como en lo referido a los estadios de desarrollo; y así se concibe que la educación moral supone un cierto proceso de maduración, una transición gradual de una estructura mental a otra estructura mental más desarrollada moralmente, cada una de las cuales tiene su peculiar modo de articular derechos y deberes en torno a lo que sea justo hacer. Entre los contemporáneos de Kohlberg, son importantes la influencia de la teoría de la justicia de Rawls y la sintonía que mantiene con las éticas discursivas, puesto que, según Habermas, tales éticas se ajustan al concepto constructivista del aprendizaje del desarrollo moral, propuesto por Kohlberg.

La teoría del desarrollo del juicio moral es una manifestación más del liberalismo ilustrado, que concibe a la persona como un individuo con dignidad inherente, fuente de sus derechos; la persona es una realidad completa en sí misma, quien a través de pactos o contratos voluntarios y racionales con otras personas, se constituye en miembro de un Estado social. El Estado tiene como función principal garantizar los derechos de cada uno de sus miembros en los conflictos de intereses que puedan producirse en la vida ordinaria. La justicia como imparcialidad es la clave de la vida política, moral y jurídica.

Quienes conciben la educación moral como desarrollo, consideran que no es función de la educación promover la adquisición de los valores morales de una 
concreta sociedad, sino estimular el progreso del juicio moral de los estudiantes mediante la discusión de dilemas morales. El esfuerzo de los educadores tiene que centrarse en generar diálogo y razonamiento sobre lo que es justo, en las situaciones conflictivas que la vida en común va planteando, y así formar una comunidad democrática y justa en el aula y en la escuela, con el objetivo de educar para la vida en una sociedad democrática. Este planteamiento educativo pone especial énfasis en las estrategias y técnicas pedagógicas que promueven la reflexión moral, la adopción del punto de vista moral (o la buena voluntad de encontrar, junto a los demás, la solución justa a los problemas), el uso del diálogo buscando el entendimiento con los otros y la autonomía moral de los sujetos.

La tercera corriente contemporánea de la educación moral, con una importante influencia en los centros de educación españoles, es la filosofía para niños. Los promotores más importantes de esta opción han sido M. Lipman y A. M. Sharp, quienes pretenden que los niños, apropiándose de los conceptos y métodos propios de la filosofía, piensen por ellos mismos en los asuntos importantes de la vida, a la misma vez que tengan interés en hacerlo.

El sustrato teórico y empírico de esta teoría de la educación moral está en la psicología constructivista de Mead, Vigostky y Bruner, para quienes el diálogo en las aulas es la clave para el desarrollo del pensamiento y la mejora de la educación. También Lipman y Sharp se consideran deudores de Dewey, de quien adoptan la estrategia de iniciar las sesiones a partir de la reflexión sobre una experiencia moral extraída de la vida cotidiana, así como la organización de los materiales escolares en la forma de un texto narrativo o novela; de Ryle y Wittgenstein siguen las recomendaciones para expresar los conceptos filosóficos en el lenguaje ordinario. Su visión de la educación tiene como referencia principal la actitud socrática en la indagación y discusión de los problemas filosóficos; actitud reflejada en el sistema de preguntas y respuestas con el que elaboran los cuadernos del alumno.

La filosofía para niños no se circunscribe a la educación moral, sino que abarca todos los ámbitos propios de la filosofía. En cuanto al tema que tratamos, se concibe la educación moral como una indagación comunitaria en desarrollo continuo y no como un conjunto de convicciones para actuar, a partir de principios o reglas; ello lleva implícito el reconocimiento de que no hay verdades morales estáticas, sino que la verdad de un principio moral está en función de su capacidad de dar origen a un mundo mejor. La integridad moral de los sujetos no es tanto un asunto de convicciones permanentes como un compromiso por el cuidado de las otras personas y de la naturaleza. La educación moral pretende que los estudiantes alcancen una percepción profunda de las situaciones problemáticas de la vida ordinaria y respondan de un modo moralmente adecuado a tales situaciones; dicho de otro modo, que los estudiantes adquieran capacidades de análisis de los problemas morales y se comprometan con la promoción de una sociedad justa y un medio ecológico equilibrado.

Esta breve síntesis de las teorías contemporáneas de la educación moral, que han merecido la atención mayoritaria de los investigadores y prácticos de la 
educación, permite algunas deducciones de interés. La primera de ellas se refiere a que las teorías de la educación moral están asentadas en tradiciones filosóficas y científicas respetadas y apreciadas en la historia del conocimiento, pero sujetas a discusión, valoración crítica y revisión como es usual en las teorías que pertenecen al ámbito de las ciencias sociales. La segunda deducción se refiere al carácter práctico de tales teorías: todas tienen la pretensión de orientar las acciones educativas para la formación de personas morales, aunque difieren en el significado de cuestiones fundamentales como la concepción de persona moral. La tercera consecuencia: todas las teorías expuestas tienen como objetivo último la moralización de la vida pública, de la vida en común; una teoría de modo central, la formación del carácter, y también las otras teorías plantean, como objetivo y justificación de la educación moral, la formación de ciudadanos competentes para la vida en sociedades democráticas y justas, aunque cada teoría tiene su propia propuesta de si tales competencias se adquieren por la interiorización de determinados valores de la comunidad política o por el desarrollo del juicio, desde principios universales, sobre lo que debe ser hecho en las situaciones moralmente problemáticas o por una correcta valoración de las situaciones sociales y un compromiso para la mejora moral de las mismas.

La cuarta consecuencia se refiere a los aspectos del sujeto que hay que atender en una adecuada educación moral, y todas las teorías son coincidentes: se han de desarrollar los conocimientos morales así como los sentimientos para que las personas sean verdaderos agentes de acciones morales en las relaciones de unos con otros y con las instituciones sociales; es cierto que cada una de las teorías insiste en un aspecto, como el más importante, y critica a las teorías rivales por resaltar otro aspecto distinto. La quinta consecuencia se refiere a que todas las teorías consideran que la educación moral no se puede dirigir a individuos aislados de sus medios sociales, sino a sujetos situados en sus contextos vitales, o dicho de otra manera, hay que intervenir a la misma vez en el sujeto y en los contextos que habita: las acciones morales como imitación de los mejores ciudadanos en la teoría de la educación del carácter, el clima moral como prerrequisito para la educación moral en la teoría del desarrollo, la comunidad de investigación para percibir y valorar la moralidad de las situaciones sociales en la filosofía para niños son los exponentes de esa postura común. La sexta consecuencia se refiere al papel especial que juegan determinadas personas como agentes de educación moral, concebidos de modo distinto en cada teoría: los ciudadanos excelentes o el profesor como modelo en la teoría del carácter; las relaciones democráticas y justas en la familia y en la escuela o el profesor como redactor de dilemas y animador de los diálogos morales en la teoría del desarrollo del juicio moral; el profesor como estimulador de la indagación, facilitador del diálogo filosófico e instigador del pensamiento autónomo en la filosofía para niños. La séptima consecuencia se refiere a la importancia que todas las teorías confieren al dominio de procedimientos, estrategias y técnicas, por parte del educador, para facilitar o diseñar los aprendizajes morales de los alumnos; asunto que ha ocupado especialmente a quienes tienen intereses pedagógicos. 


\section{LA ACTUAL INVESTIGACIÓN EN EDUCACIÓN MORAL}

Mediados los años noventa del siglo pasado, se producen nuevos rumbos en la investigación de la educación moral. En mi opinión, tres son los fenómenos sociales que están en la base de esos cambios. Uno de ellos es el interés por dar respuestas moralmente válidas a los graves problemas que afectan a la convivencia en las sociedades complejas de nuestro tiempo: la violencia, la droga, las migraciones, el hambre, el deterioro de la Naturaleza y las guerras. Otro, la globalización que plantea nuevos problemas a los que es necesario dar respuestas morales en la educación de los ciudadanos. El tercero, el desarrollo de la conciencia colectiva sobre la necesidad de promover la vigencia de los derechos humanos y la consideración de los valores, que sustentan a esos derechos (la dignidad humana, la libertad, la igualdad y la solidaridad), como los grandes ideales que tendrían que ser aceptados y regir los comportamientos morales de todos los individuos, las instituciones y los gobiernos.

La búsqueda de una efectiva educación moral implica que muchos de los investigadores abandonan la ortodoxia de las teorías en las que estaban encuadrados y usan elementos pertenecientes a una u otra teoría, siempre que sirvan para organizar y justificar sus programas educativos, de los que se intenta probar la eficacia para obtener lo que pretenden. Se produce un sincretismo tanto teórico como en los procedimientos y técnicas pedagógicas con los que se interviene. Otros investigadores hallan la justificación de sus programas de acción educativa en pensadores de nuestro tiempo, que han reflexionado sobre los problemas morales que anteriormente he mencionado. Así, aparecen, en los discursos teóricos sobre educación moral, referencias a filósofos contemporáneos o a otros filósofos, consagrados en la historia del pensamiento, que no eran usuales en los discursos teóricos de los años noventa.

Una muestra de ese sincretismo teórico se manifiesta en el acuerdo, hoy generalmente compartido, sobre los aspectos que es necesario formar para que una persona esté educada moralmente: la conducta, el carácter, el conocimiento de los valores morales, el razonamiento práctico y las emociones. La conducta moral es la finalidad que persigue toda educación moral; tal conducta se debe aprender, practicar e interiorizar hasta constituir una forma de ser del sujeto, o carácter, que se manifiesta en sus comportamientos privados y públicos; el conocimiento de los valores morales es necesario, puesto que hacen a nuestra sociedad y a nuestro mundo habitables y a la altura de la dignidad humana; el razonamiento práctico, ya que una persona moralmente madura tiene que ser capaz de reflexionar sobre un problema, del que se derivan perjuicios o beneficios para las personas o para la sociedad, y emitir un juicio moral racional al respeto; y las emociones que son la raíz del dinamismo de la persona. Es difícil encontrar un investigador o práctico de la educación que no esté de acuerdo en la necesidad de la educación moral de todos esos aspectos. 
El proceso de globalización creciente en la economía, en la información y comunicación, en la cultura y en la política nos exige un modo de pensar nuevo sobre viejos problemas morales como el hambre y las guerras. Lo que hoy se necesita son soluciones eficaces para un mundo siempre más interdependiente y más en riesgo. La educación moral, desde sus inicios, ha pretendido formar competencias en los sujetos para la acción en sus comunidades políticas. Lo que está aconteciendo actualmente es un cambio profundo en la conformación de las comunidades políticas que, por un lado, traspasan los límites de la nación y del Estado y, por otro, se hacen más plurales y heterogéneas. Desde la interdependencia de unos países con otros, de unas regiones políticas con otras; desde la estructura planetaria y reticular de la información, de la economía, del conocimiento y de la política; desde la mezcla de gentes con culturas diversas que habitan una misma ciudad, surgen problemas nuevos para los que no hay antecedentes morales con los que responder. Ello conduce a la búsqueda de nuevos planteamientos y enfoques que, como es razonable, se producen junto a planteamientos y enfoques sustentados en las teorías de la educación moral, anteriormente reseñadas.

\section{LOS CONTENIDOS DE ESTE MONOGRÁFICO}

Los artículos que se publican en este monográfico son una buena muestra de la pluralidad de tales puntos de vista. Hay tres bloques de contenidos: cuatro artículos tratan temas claves de la investigación moral en los últimos cincuenta años que, por su importancia, seguirán siendo objeto de preocupación y estudio en los años venideros como la educación moral y la familia, la educación moral en el contexto de la escuela y la formación del profesorado, el diseño de programas de aula para la educación moral y la delimitación de las competencias que configuran la personalidad moral; tres artículos plantean problemas morales de todos los tiempos como las guerras, el hambre y la convivencia civil que, en las sociedades complejas e interdependientes de un mundo globalizado, exigen una comprensión nueva y respuestas morales actualizadas; dos artículos tratan sobre ética profesional que, aunque son una novedad entre los teóricos de la educación, hace tiempo que tendría que cultivarse. No se entiende bien que hayamos prestado tan poca atención a la educación para el desempeño ético de las profesiones, de tanta importancia en el funcionamiento de las sociedades modernas.

A pesar de los contextos plurales y heterogéneos que actúan como agencias educativas y socializadoras, los profesores P. Ortega y R. Mínguez defienden que la familia es el marco más adecuado para el aprendizaje de valores, de patrones valiosos de conducta; cuando fracasa en ese cometido, resulta muy difícil su suplencia. Los niños que van a nuestras escuelas vienen ya equipados con unos determinados valores (y antivalores), a través de los cuales filtran las inevitables propuestas valorativas que la escuela realiza a diario. Ninguna de ellas dejará de estar interpretada por el modo de pensar y vivir de la propia familia. Las actitudes 
y creencias, los valores y antivalores están en la base de lo que el niño piensa y hace. Y los valores y antivalores del niño conectan con el medio familiar. La pedagogía de los valores en el ámbito familiar es considerada por estos autores como fundamental.

En su artículo exponen las condiciones ambientales de la familia para que se produzca el aprendizaje de los valores: la función de acogida, el clima moral y el diálogo. La acogida en la familia significa para el niño sentirse protegido por el amor y el cuidado de sus padres; sentir cercana la presencia de los padres que se hace dirección, guía y acompañamiento; en la acogida por los padres, el niño experimenta la vivencia de valores morales como el reconocimiento respetuoso, la responsabilidad y la entrega. El clima moral no se limita a dar cuenta de aquello que hacemos u omitimos porque alguien nos lo demanda, sino que también implica el cuidado, la atención y la solicitud de unos por los otros. El diálogo, como comunicación de la experiencia vital de los interlocutores, tiene en la familia un lugar privilegiado; las narraciones de las experiencias vividas por unos y otros son recursos poderosos para la educación en valores.

El trabajo de los profesores M. Martínez, J. M. Puig y J. Trilla analiza cuatro temas de interés indudable: las propuestas legales relacionadas con la educación cívica y moral; los diferentes espacios de educación moral en la escuela; el debate de la formación religiosa y su relación con la educación en valores y las necesidades que tiene el profesorado para la educación moral. El análisis de las diferentes propuestas legales a partir del siglo xx (Preconstitucionales, Constitución, LOECE, LODE, LOGSE, LOCE) les lleva a afirmar que la educación moral institucionalizada en el sistema educativo, al menos como ellos la entienden, exige libertad de conciencia y de expresión, tolerancia y aceptación del pluralismo ideológico, en definitiva, un marco democrático. Por ello en España, salvo en algunos momentos históricos y de corta duración, no se ha diseñado correctamente el espacio de la educación moral en la escuela hasta el advenimiento del actual Estado democrático. La LOGSE parece asignar a la educación moral un papel notable, pero la propia ley y los desarrollos que surgieron de ella propiciaron unos considerables márgenes de indefinición y ambigüedad, no resueltos sino aumentados con la LOCE.

La educación en valores en la escuela se produce en diversidad de momentos, actividades, encuentros, vivencias, con plurales recursos y métodos. Los autores ordenan, con una argumentada justificación, este caos aparente en cuatro espacios que denominan: el de las relaciones interpersonales, el de las tareas escolares, el de la cultura escolar y el comunitario. En cuanto al debate de la formación religiosa y la educación en valores, que ya anuncian en la primera parte, justifican la posición siguiente: aceptan como contenido curricular el conocimiento y la reflexión sobre el hecho religioso, como fenómeno cultural; desvinculan la educación religiosa confesional del currículo formal; proponen un Proyecto Educativo de Centro que se abra a la colaboración de la comunidad civil para que puedan desarrollarse actividades de educación religiosa orientadas según las diferentes confesiones presentes en esa comunidad. Creo que tal propuesta merece ser analizada como una 
solución posible al enconado debate que vivimos. La formación del profesorado para una adecuada educación moral es argumentada en su necesidad y señalados los contenidos de tal formación, que no tienen que referirse sólo a técnicas y recursos sino, en especial, a la formación del profesorado en tanto que educador en cuestiones éticas, gestor de convivencia, tutor y orientador de padres y madres como educadores morales.

La profesora C. Nuévalos presenta los resultados de un programa de educación moral, siguiendo los principios teóricos, la discusión de dilemas, el instrumento de medida de Rest (DIT) y el procedimiento de análisis de la teoría del desarrollo del juicio moral. Además del correcto diseño del programa, merece resaltarse el hecho de su aplicación a estudiantes universitarios de Magisterio en la asignatura «Pedagogía de los valores y las actitudesw. Los objetivos que se propone la autora son tanto fomentar el desarrollo moral de los estudiantes de Magisterio como mejorar su competencia profesional en el ámbito de la educación moral para que ellos mismos, en un futuro, sepan diseñar programas para el desarrollo del juicio moral.

La construcción de la identidad personal como proyecto de educación moral es la tesis central que defiende el artículo del profesor A. Bernal. Tres son las partes que articulan su exposición: en la primera, hace un estudio de la noción de sujeto, argumentado desde autores relevantes del pensamiento actual, que le lleva a afirmar "este yo es quien percibe, recuerda, se emociona, anda, corre, se alimenta, disfruta, afronta la realidad y aun la transforma, emplea el lenguaje y es capaz de comunicarse con otros, aunque se trata de un yo imperfectamente unificado y acaso no jerarquizado. En la segunda parte, presenta su concepción de competencias de la persona como acciones intencionales, que se refieren no únicamente a las tareas o habilidades que se ejecutan, sino también a la comprensión de las situaciones problemáticas que el sujeto debe afrontar; en este sentido, las competencias presentan un carácter general fundado en su relación con la personalidad del sujeto. La educación moral precisamente se puede vincular al núcleo de ese yo competente, y deviene en determinante de competencia generalizada. En la tercera parte, A. Bernal desarrolla la justificación de una propuesta pedagógica de formación de competencias para la construcción del sujeto desde una perspectiva moral: poseer sentido crítico, tener criterio propio, presentar sensibilidad emocional, manifestar prosocialidad y mostrar sentido creativo en el ámbito de los valores. Considera que, a través de estas competencias generales, se desarrolla un complejo entramado de capacidades como el juicio moral, la autorregulación, el control y gestión de las emociones, entre otras.

F. Gil, G. Jover y D. Reyero articulan su trabajo en torno a una pregunta fundamental: ¿qué puede hacer la educación moral ante las guerras y los conflictos? La respuesta que ofrecen está enmarcada en una línea de investigación que cultivan desde 1997 sobre pedagogía infantil, dirigida a esclarecer aspectos relacionados con la educación moral, la educación cívica y la imagen que los niños tienen de otros niños. El artículo muestra el proceso de investigación empírica sobre cómo transforman los niños la visión de unas fotografias, de niños en situación de 
guerra, en ideas sobre el sufrimiento y la guerra. Los resultados de la investigación ofrecen una esperanza en estos momentos de incertidumbres y amenazas: los niños consideran que las guerras no tienen sentido, ninguna utilidad, ni encuentran razón alguna que las justifique.

Los autores del artículo consideran que los investigadores y educadores morales no somos potenciales salvadores del mundo, pero sí tenemos el deber de investigar y hacer propuestas para mejorar las situaciones inmorales. La educación para la paz requiere la promoción de sentimientos y actitudes de solidaridad y empatía hacia los otros. Así mismo, requiere un conocimiento, adaptado a las capacidades de los niños, sobre las causas que ayudan a entender los conflictos humanos. Ambas dimensiones son necesarias para aprender a leer, analizar y responder las informaciones e imágenes que proporcionan los medios de información. Sólo si se trabajan ambas se podrá conseguir una educación para la paz que evite tanto el voluntarismo sensiblero como el racionalismo insensible. Deseo resaltar la síntesis que los autores hacen del proceso de la investigación sobre educación moral, que se ha llevado en el área de Teoría de la Educación de las universidades españolas. Parece como si pasaran de puntillas por esta aportación, que no mencionan en el resumen, pero de interés para quienes nos dedicamos a estos asuntos.

El artículo de los profesores J. Escámez, R. García y C. Pérez trata de la pobreza en el mundo, especialmente de la pobreza severa, y el reto que presenta a la educación moral. Los autores consideran que los informes de los organismos internacionales sobre la pobreza tienen que dar lugar a debates en la sociedad civil, que sus miembros tomen conciencia de la inmoralidad de la situación y presionen a los dirigentes de los gobiernos e instituciones, donantes o receptores de ayuda internacional, para que lleven a cabo las reformas políticas y económicas que solucionan o aminoran esa lacra moral. La parte central del artículo argumenta cinco propuestas pedagógicas de prácticas morales que generan en los estudiantes competencias como ciudadanos comprometidos en la erradicación de esa vergüenza política y moral. Tales propuestas pedagógicas están referidas al desarrollo sostenible, la cooperación internacional, el consumo justo y responsable, el servicio voluntario a la sociedad y la participación política.

El profesor J. M. Touriñán analiza las propuestas de multiculturalidad e interculturalidad, que se han venido haciendo a partir de los años noventa, y concluye que el interculturalismo profundiza en la idea de la convivencia y el avance de la penetración cultural, mientras que el multiculturalismo se contrapone al pluralismo y hace prevalecer el efecto de la separación frente a la inclusión. El autor cree que la educación sigue siendo un camino adecuado para la integración intercultural de la sociedad civil, puesto que puede preparar individuos capaces de combinar la cultura universalizada y circundante, capaces de desplazamientos de una a otra sin problemas, siempre que acepten y comprendan al otro, culturalmente diferente, como un igual en dignidad. En el fortalecimiento de esta tendencia, hacia la comprensión y aceptación del otro, está el origen del sentido más básico de la relación entre libertad personal y sociedad, puesto que el sujeto no sólo respeta las leyes de una sociedad pluralista e intercultural, sino que comprende las razones éticas que la justifican. 
El autor considera que la manifestación más genuina de la acción de la sociedad civil como agente moral es la moral civil, que cumple una función identificadora, conformadora y legitimadora de la vida social en convivencia, en función de lo que deben hacer los ciudadanos para ser justos y consecuentes con una ética cívica de mínimos que defienda los derechos humanos y propicie la formación en los valores que subyacen en el ejercicio de esos derechos.

La Dra. A. Hirsch tiene una amplia experiencia en la investigación sociológica sobre valores de los universitarios y profesionales de México. En su artículo argumenta, con doce buenas razones, la importancia de la formación ética de los profesionales en las instituciones de educación superior; presenta el estado de la investigación, hasta el año 2002, sobre valores universitarios y profesionales de los mexicanos; describe los principios fundamentales de la ética profesional y los rasgos del ethos profesional.

En su artículo, J. M. Cobo defiende que la universidad debe preparar a los estudiantes para un ejercicio ético de la profesión, puesto que las profesiones nacen para proporcionar algún bien (productos o servicios) a la sociedad. La ética profesional, que debe transmitir la universidad, tiene como objetivo tomar conciencia del bien que corresponde realizar a la profesión de la que se trata, de tal modo que procediendo de acuerdo a ese bien se adquiera la experiencia del sentido de lo que se hace, y el conocimiento de las normas sobre cómo conducirse en la vida profesional. El autor describe y argumenta los principios éticos que han de regular los comportamientos profesionales. Hace una presentación pedagógica de los diferentes bloques de contenidos (conocimientos, valores y actitudes profesionales) que deben ser tratados en la asignatura de la ética profesional en la universidad, así como las sugerencias metodológicas para su enseñanza y aprendizaje.

El profesor Cobo finaliza su artículo con referencias a la situación de la enseñanza de la ética profesional en las universidades españolas. Tales referencias son organizadas en torno a tres ideas principales: hay una sensibilidad creciente sobre la necesidad de incluir la ética profesional en el currículum de la educación universitaria; hay ya experiencias importantes de esta inclusión de la ética profesional en el currículum en algunas titulaciones y universidades; proliferan otras muchas experiencias que hacen presente la ética profesional en la educación superior.

Deseo hacer constar mi agradecimiento a todos los que han participado en este monográfico con sus trabajos, así como las sugerencias y correcciones a los mismos formuladas por la Dirección y el Comité Científico de la Revista Interuniversitaria de Teoría de la Educación. De los artículos aquí publicados, tres no fueron solicitados y, sin embargo, recibieron un juicio positivo por su calidad científica. Algunos investigadores de Teoría de la Educación fueron invitados a participar y declinaron la oferta; otros podrían haber contribuido con aportaciones excelentes, dada la calidad de los trabajos que han publicado en este ámbito disciplinar, pero diversas circunstancias lo impidieron. En mi opinión, los trabajos que presenta este número son una muestra representativa y significativa del vigor e interés de los profesores universitarios de Teoría de la Educación en la educación moral. 